\title{
Efeito da pandemia causada pelo covid-19 no market share brasileiro: um enfoque segundo os tipos de modal de transporte
}

\author{
Effect of the pandemic caused by covid-19 on the brazilian market share: an approach according to \\ the types of transport mode
}

Efecto de la pandemia causada por el covid-19 sobre el market share brasileño: un enfoque a partir de los tipos de modal de transporte

\author{
Fernando Andrade Guidorizzi \\ ORCID: https://orcid.org/0000-0002-2650-195X \\ Universidade Federal de Mato Grosso do Sul, Brasil \\ E-mail: fernandoguidorrizzi@gmail.com \\ Gabriel Ribeiro Mendes \\ ORCID: https://orcid.org/0000-0001-5302-125X \\ Universidade Federal de Mato Grosso do Sul, Brasil \\ E-mail: gabrielmendes9815@gmail.com \\ Josué Pires de Carvalho \\ ORCID: https://orcid.org/0000-0002-9611-2693 \\ Instituto Federal de Brasilia, Brasil \\ E-mail: josue.carvalho@ifb.edu.br \\ Jorge Luis Sánchez Arévalo \\ ORCID: https://orcid.org/0000-0002-8426-2096 \\ Universidade Federal de Mato Grosso do Sul, Brasil \\ E-mail: jsarevalo@alumni.usp.br
}

\begin{abstract}
Resumo
O estudo teve por objetivo analisar o padrão do comércio exterior brasileiro no período pandêmico, ante tal, verificar mudanças segundo os principais modais de transporte utilizados tomando como objeto de estudo os estados com maior mobilidade exportadora. As informações utilizadas tem como fonte o Ministério de Comércio Exterior por meio da plataforma comexstat. O tempo de estudo compreende ao intervalo de 2018 a 2020, a finalidade foi verificar possíveis ganhos ou perdas de market share via modal de transporte e, para tal finalidade se utilizou o modelo de market share em sua forma reduzida. Por meio dos resultados se verificou resultados relevantes, como mudanças no modal aéreo no caso do estado de São Paulo e Minas Gerais e, ganhos de market share no caso de São Paulo. Também, os resultados retratam a relevância do modal marítimo como essencial no padrão da pauta exportadora, além disso, o destaque do estado de São Paulo na participação total exportada pelo país. No geral, foi possível traçar um efeito substancial na pauta exportadora atrelada aos efeitos da crise sanitária causada pelo covid-19.
\end{abstract}

Palavras-chave: Comércio; Modal de transporte; Market share; Crise econômica.

\begin{abstract}
The study aimed to analyze the pattern of Brazilian foreign trade in the pandemic period, in view of this, to verify changes according to the main modes of transport used, taking as object of study the states with greater export mobility. The information used is sourced from the Ministry of Foreign Trade through the comexstat platform. The study time comprises the interval from 2018 to 2020, the purpose was to verify possible gains or losses in market share via transport mode and, for this purpose, the market share model was used in its reduced form. Through the results, relevant results were verified, such as changes in the air modal in the case of the state of São Paulo and Minas Gerais and market share gains in the case of São Paulo. Also, the results portray the relevance of the maritime modal as essential in the pattern of the export agenda, in addition, the highlight of the state of São Paulo in the total share exported by the country. In general, it was possible to trace a substantial effect on the export agenda linked to the effects of the health crisis caused by covid-19.
\end{abstract}

Keywords: Trade; Transport mode; Market share; Economic crisis.

\section{Resumen}

El objetivo del estudio fue analizar el patrón del comercio exterior brasileño en el período pandémico, en vista de aquello, verificar cambios en los principales modos de transporte utilizados tomando como objeto de estudio los estados con mayor movilidad exportadora. La información utilizada tiene como fuente el Ministerio de Comercio 
Exterior a través de la plataforma comexstat. El tiempo de estudio comprende el intervalo de 2018 a 2020 , y el propósito fue verificar posibles ganancias o pérdidas de participación de mercado por tipo de transporte y, para ello, se utilizó el modelo de market share en su forma reducida. De acuerdo con los resultados, se verificaron resultados relevantes, como cambios en el modal aéreo en el caso del estado de São Paulo y Minas Gerais y ganancias de participación de mercado en el caso de São Paulo. Asimismo, los resultados retratan la relevancia del modal marítimo como esencial en el patrón de la agenda exportadora, además, el destaque del estado de São Paulo en la participación total exportada nacional. En general, fue posible rastrear un efecto sustancial en la agenda de exportación vinculada a los efectos de la crisis sanitaria causada por el covid-19.

Palabras clave: Comercio; Modo de transporte; Market share; Crisis económica.

\section{Introdução}

Com a crise sanitária vivenciada desde março de 2020, diversas medidas foram adotadas pelo governo com a finalidade de conter o avanço da doença no mundo, sendo uma das medidas o fechamento das fronteiras, cancelamento de voos e fechamento das atividades comerciais que possam causar aglomeração. Esse cenário trouxe consigo muita incerteza sobre o futuro da economia, a eficácia das vacinas a curto prazo e retomada da economia (Borca, Putz \& Hofbauer, 2021; Notteboom, Pallis \& Rodrigue, 2021; Ashwani, 2020; Loaiza et. al. 2020).

Nesse processo de adoção de medidas e o efeito substancial nas cadeias produtivas da economia, afetou contemporaneamente as atividades de transporte de todos os modais de transporte, quer seja marítimo, rodoviário ou aéreo (Pereira, et. al. 2021; Nimorakiotaki \& Sambracos; 2020). No caso de cenário brasileiro, esses três modais são essências e responsáveis pela troca de comércio, tanto interno como externo, sendo o mais relevante o modal marítimo para o comércio exterior (MDIC, 2021).

De acordo com informações da ONU (2020), aproximadamente 80\% do comércio global é realizado via o modal marítimo. Em vista da crise pandêmica e seus efeitos nas cadeias de produção, o organismo em tela prevê que um efeito substancial do aumento das taxas de transporte marítimo nos preços dos produtos para o consumidor final, sinalizando ante tal, um efeito mundial de inflação (Pinto et al., 2021; Bresser-Pereira, 2020).

No caso do Brasil, os modais mais representativos são o marítimo, aéreo e rodoviário os quais representam aproximadamente $99 \%$ nas operações de comércio exterior (MDIC, 2021). Nesse ponto, e dado a rápida adoção de medidas sanitárias visando atender os protocolos de saúde os portos para exportação operaram normalmente durante a crise, sendo que com menor fluxo. Essa adoção foi fundamental e determinante para que setores como o agronegócio na qual o Brasil é um grande fornecedor ao mundo obtivesse bons desempenhos em receita (MAPA, 2021).

Outro setor de destaque foi o minério, que no período pandêmico as empresas vinculadas aso setor obtiveram bons desempenhos. De acordo com informações do IBRAM (2021) a China é o principal mercado destino do total das exportações desse produto, sendo que em 2019 esse país respondeu por 62\% das exportações e em 2020 a participação foi de 72\%, aproximadamente.

Em face ao discutido, o estudo se justifica por abordar de forma geral a relevância dos modais de transporte nas trocas de comércio em uma economia. Ao mesmo tempo, revelar mudanças comparativas por estados em um intervalo curto de tempo. Dessa forma, o estudo tem por objetivo verificar mudanças de participação no comércio exterior por modais de transporte, a qual no estudo é definido como market share. A saber, o estudo incorpora uma comparação entre os principais estados de origem das exportações em relação ao total exportado pelo país, bem como, os efeitos da crise entendido como uma mudança estrutural no sistema econômico. 


\section{Revisão Bibliográfica}

\subsection{Comércio brasileiro via tráfego aéreo}

Na Figura 1, se verifica o comportamento mensal da série exportação via modal de transporte aéreo entre o período de janeiro de 2019 a dezembro de 2020. Na figura em tela, é possível observar uma quebra de estrutura em março de 2020, atrelado esse comportamento a crise sanitária causado pelo covid-19. Entende-se por quebra estrutural como uma mudança no nível da série, quer seja de dispersão ou inclinação, no caso em questão verifica-se uma mudança repentina da tendência.

Com a queda dos voos internacionais e nacionais no período de lockdown as exportações nacionais via modal aéreo despencaram 67\% aproximadamente, entre março e abril de 2020 (Vide figura 1). Evidentemente, a queda de voos comerciais prejudicou muito as exportações já que em muitos casos esses voos destinam cerca de $30 \%$ do porão das aeronaves ao transporte de cargas (CBPCE, 2021).

Embora os efeitos da crise tenham sido relevantes para esse modal de transporte, verifica-se que conforme a figura 1, que até dezembro de 2021 o valor exportado tende-se a se aproximar a patamares de dezembro de 2020, porém com menor quantidade exportada. Esse comportamento pode indicar, entre outros, que o preço exportado em média ficou mais caro no período pandêmico.

Figura 1 - Comportamento da exportação via modal aéreo. Quantidade e valor FOB US\$, 2019 a 2020, série mensal.

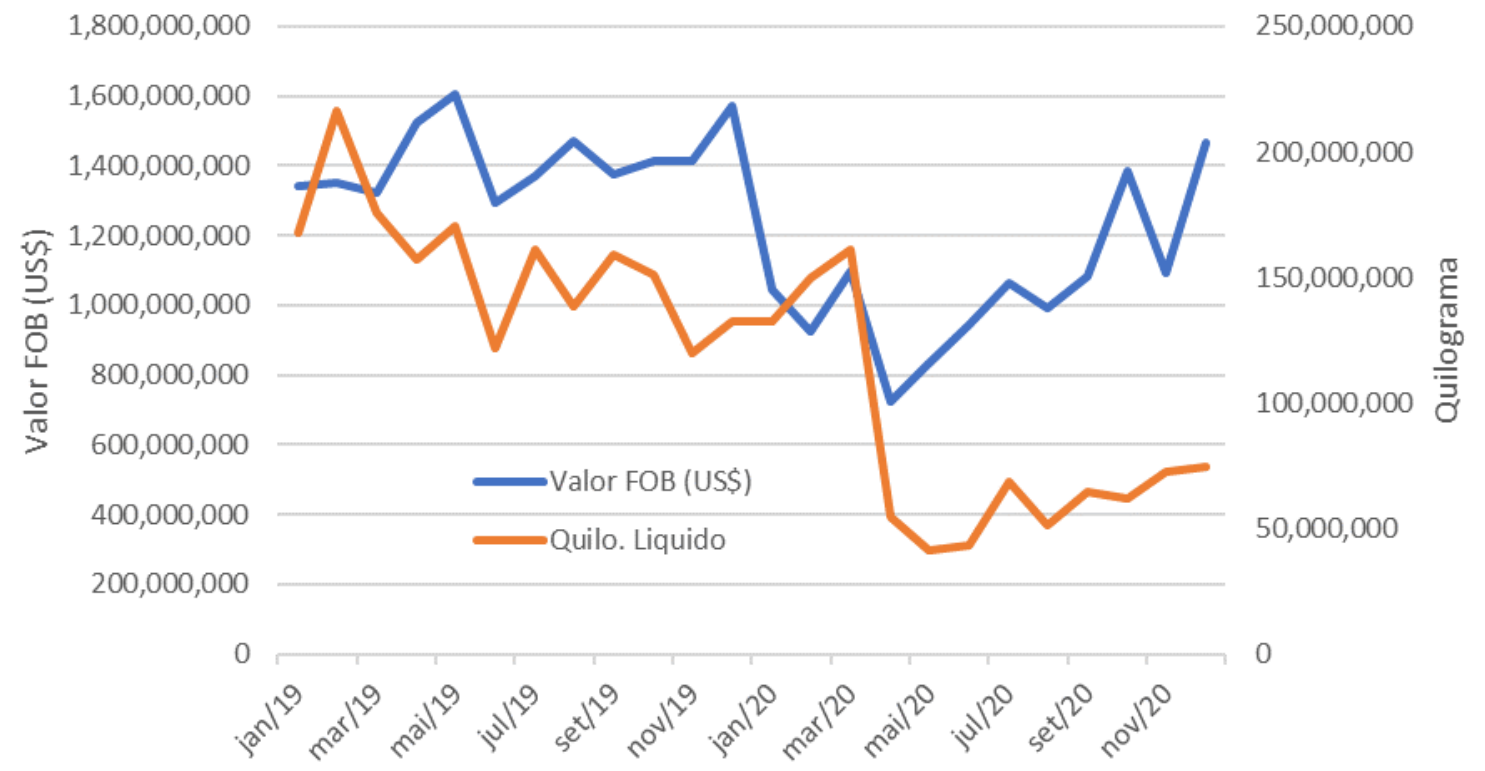

Fonte: Elaborado com dados do MDIC (2021).

De acordo com o MDIC (2021), o setor da indústria nacional brasileira exporta a maior parte de seus produtos mais caros por via aérea. Além disso, o uso do modal citado em tela para a exportação de produtora básicos caiu muito nos últimos anos, sendo mais habitual nesse caso o uso do modal marítimo. De acordo com informações do CNI (2020), o uso do modal aéreo caiu de 18,7\% para 11\% entre o ano 2000 a 2018, sendo os principais destinos Estado Unidos e a União Europeia, com participação de $60 \%$, aproximadamente. No total geral exportado pelo país, esse modal representou o 6,05\% das exportações em 2020 (MDIC, 2021).

Dentre os principais produtos exportados por este modal tem-se reatores nucleares, caldeiras e máquinas, pedras preciosas, aeronaves e aparelhos espaciais, aparelhos e materiais elétricos, aparelhos e instrumentos de óptica e fotografia, que no geral representam $80 \%$ aproximadamente do total exportado via esse modal (MDIC, 2021). 


\subsection{Comércio brasileiro via tráfego marítimo}

Na figura 2, se verifica o comportamento da série exportação do Brasil via modal marítimo segundo valor FOB US\$ e quantidade. A diferença da figura 1, na figura 2 se observa que o efeito da crise foi menos substancial, embora exista uma quebra de estrutura no mês de março de 2020, nos meses seguintes a série tende ao mesmo patamar do ano de 2019.

O transporte marítimo é responsável por aproximadamente $95 \%$ das trocas de comércio, contando exportação e importação e em 2020, foi responsável por aproximadamente 88,09\% das exportações (MDIC, 2021) e, o modal de transporte também se viu afetado com a paralisação em razão da pandemia da covid-19, porém em menor magnitude quando comparado ao modal aéreo e rodoviário. Para o primeiro trimestre, no ano de 2020 respeito a 2019, as trocas de comércio exterior tiveram uma redução de 20\% (ANTAQ, 2021).

Figura 2 - Comportamento da exportação via modal marítimo. Quantidade e valor FOB US\$, 2019 a 2020, série mensal.

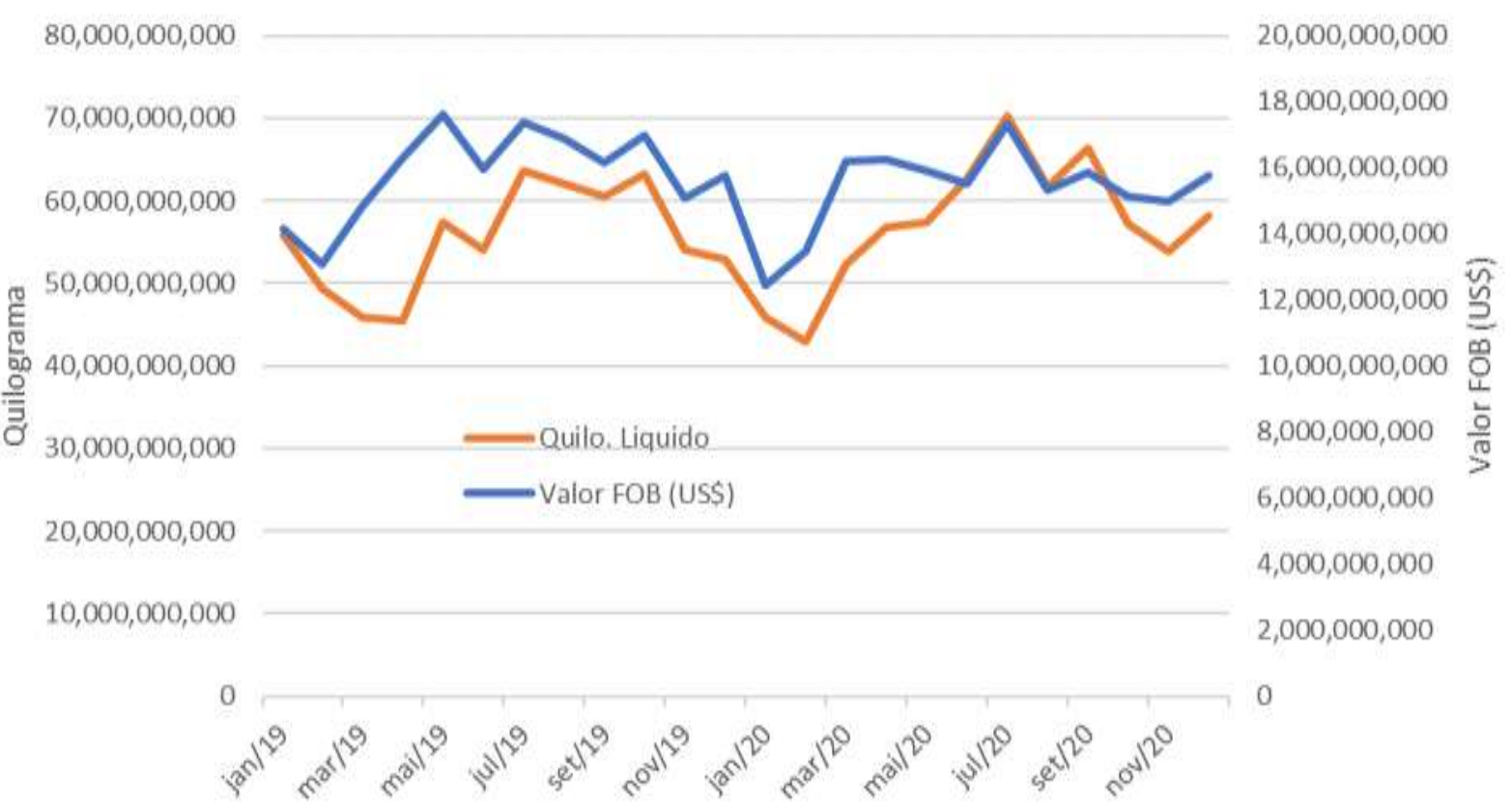

Fonte: Elaborado com dados do MDIC (2021).

Com a expansão da doença no mundo e a chegada nas Américas, a preocupação dos agentes do mercado com os novos desafios impostos no comércio mundial atrelados a exigência sanitária, girava em torno da rápida operacionalização para que os portos mantenham as condições necessárias para que fluxo de comércio se realize. As medidas de prevenção foram determinantes para que no Brasil os portos e terminais portuários operassem com normalidade em 2020, o que facilitou o bom desempenho exportador nesse período (ANTAQ, 2021). De acordo com o CNI (2021), no período pandêmico a utilização dos itinerários pré-definidos para o transporte de contêineres operava moralmente, embora em menor número quando comparados com o primeiro trimestre de 2019.

\subsection{Comércio brasileiro via tráfego rodoviário}

No ambiente acadêmico existe um longo debate que ao mesmo se canaliza em um consenso, o qual denota ao transporte como um termômetro de toda economia. Em muitos casos, a greve de caminheiros no Brasil é vista como um entrave para a economia, já que o movimento de mercadorias e matérias primas é muito mis intenso via modal rodoviário, além disso, boa parte do escoamento das safras nacionais, utiliza essa logística para exportação. 
Na Figura 3, se observa que o comércio externo brasileiro via modal rodoviário se viu afetado com mais assiduidade entre os meses de março e abril de 2020, contexto similar aos verificados aos outros modais de transporte. Entretanto, desde o mês de maio as exportações em quantidade aumentaram substancialmente, na figura 3 , se observa um distanciamento da série valor exportado FOB, a saber, o preço de exportação em média ficou mais barato.

Figura 3 - Comportamento da exportação via modal rodoviário. Quantidade e valor FOB US\$, 2019 a 2020, série mensal.

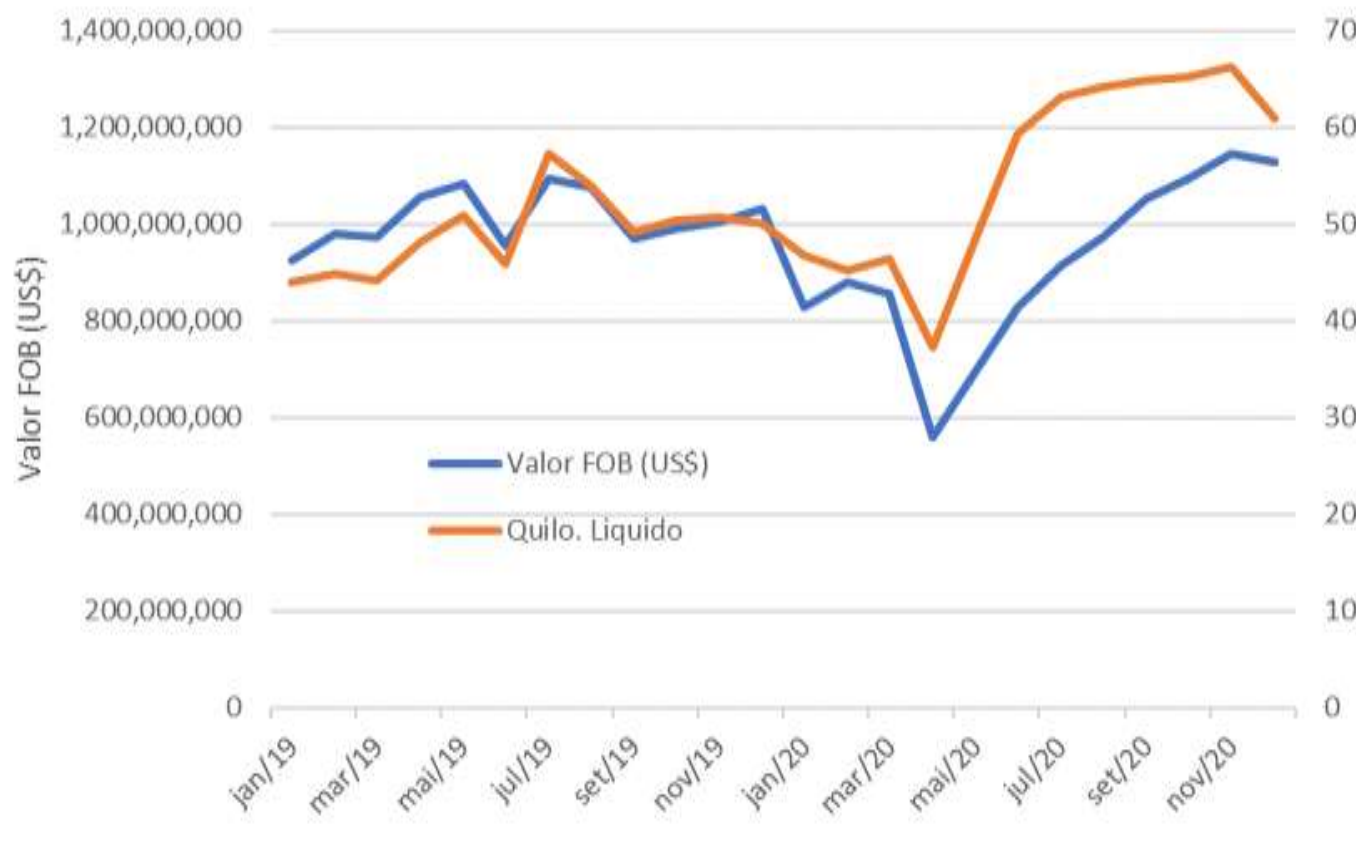

$700,000,000$

$600,000,000$

$500,000,000$

$400,000,000$

$300,000,000$

$200,000,000$

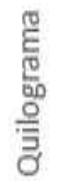

Fonte: Elaborado com dados do MDIC (2021).

Dentre outros aspectos, um dos determinantes para esse desempenho foi a rápida implementação de protocolos de segurança, como a aferição de temperatura, o teletrabalho, higienização de cabines de caminhões e outras tantas orientações de higiene, com a finalidade de controlar a disseminação do vírus (ABTI, 2021). Em geral, em 2020 o modal de transporte em tela foi responsável por aproximadamente 5,24\% das exportações brasileiras (MDIC, 2021).

\section{Desempenho exportador segundo modal de transporte. Estados com maior participação no total Brasil.}

3.1 Transporte marítimo. Estados de São Paulo, Rio de Janeiro e Minas Gerais.

Neste item se discute a mudança percentual experimentada via transporte marítimo pelos estados de São Paulo, Rio de Janeiro e Minas Gerais. Para esta discussão, previamente se realizou um levantamento dos dados por estados e via modal de exportação e, dessa forma, os estados em tela foram escolhidos no estudo.

A Figura 4, por meio da cor verde retrata as mudanças mensais observadas em 2019 respeito a 2018. No caso do estado de São Paulo, a maior parte dos meses indicam que o percentual exportado em 2019 via esse modal foi menor em relação a 2018, verificando-se similar desempenho em 2020, respeito a 2019.

No caso do estado de Rio de Janeiro, no ano de 2020 respeito a 2019 verifica-se uma retração das exportações entre os meses de abril até dezembro, salvo no mês de julho uma variação positiva. Para esse mesmo período, até o mês de março as exportações denotavam um saldo positivo, chegando a uma variação de $60 \%$, aproximadamente, no mês de fevereiro. No ano de 2019 respeito a 2018, chama a atenção a mudança observada no mês de dezembro, na qual a variação chegou até $100 \%$, 
Research, Society and Development, v. 11, n. 1, e26111124732, 2022

(CC BY 4.0) | ISSN 2525-3409 | DOI: http://dx.doi.org/10.33448/rsd-v11i1.24732

aproximadamente. Mudanças positivas também se observa nos meses de março a junho. No geral, não se observa um padrão de variação positiva constante, o desempenho tende a mudar em vários meses dos anos.

Para o período de 2020 respeito a 2019, as exportações via modal marítimo que tem como origem o estado de Minas Gerais revela um padrão de comportamento diferente aos outros estados ao verificar os meses de setembro a dezembro. Para o estado de Minas Gerais, os meses em tela significou a retomada das exportações, já que no geral, entre os meses de janeiro até agosto o desempenho ficou negativo. Também, no ano de 2019 respeito a 2018, verifica-se nos últimos meses do ano uma retração da variação exportadora, algo que foi repassado paro o ano seguinte. Ainda no mesmo período, é notório observar uma variação positiva acumulada entre os meses de janeiro até agosto 
Research, Society and Development, v. 11, n. 1, e26111124732, 2022

(CC BY 4.0) | ISSN 2525-3409 | DOI: http://dx.doi.org/10.33448/rsd-v11i1.24732

Figura 4 - Mudança percentual nas exportações via modal marítimo valor FOB US\$, estados de São Paulo, Rio de Janeiro e Minas Gerais. 2018-2019, 2019-2020.
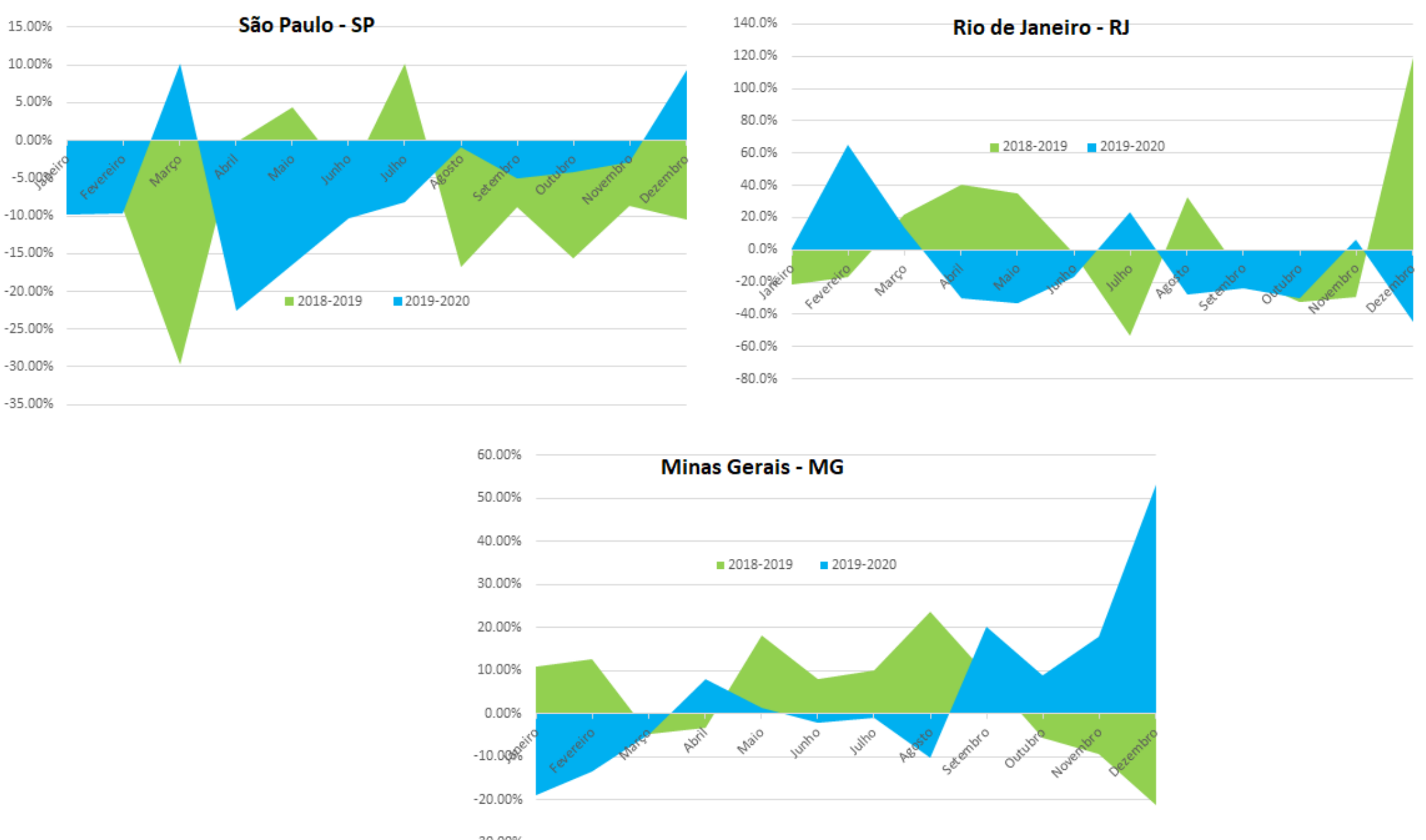

Fonte: Elaborado com dados do MDIC (2021). 
Research, Society and Development, v. 11, n. 1, e26111124732, 2022

(CC BY 4.0) | ISSN 2525-3409 | DOI: http://dx.doi.org/10.33448/rsd-v11i1.24732

\subsection{Transporte rodoviário. Estados de São Paulo, Rio de Janeiro e Minas Gerais.}

No caso do transporte rodoviário, a importância desse modal radica no fato de ser o principal meio de transporte interno utilizado no país (MINFRA, 2021). E na figura 5 se observa as mudanças no padrão de exportação dos estados objeto de discussão para os anos de 2018 a 2020, considerando dois intervalos de tempo, tal como retratado na figura em tela.

No caso do estado de São Paulo, no intervalo de 2019/2018 não se observa mudança positiva no padrão de exportação via o modal rodoviário e, de forma similar, para 2020 em relação a 2019 para os meses de janeiro até agosto a situação é negativa. Somente, no intervalo dos meses de setembro a dezembro de 2020 em relação a 2019 se verifica uma mudança positiva.

No geral, para 2020 respeito a 2019, variações similares são observadas para os estados de Rio de Janeiro e Minas Gerais, com diminuição na pauta de exportação via esse modal no primeiro e aumento no segundo semestre. Esse comportamento denota que eventuais eventos que afetem o comportamento do modal de transporte são canalizados na mesma direção pelos três estados objeto de discussão.

Em informação publicada pelo CNT (2020), tal organismo ressaltou os efeitos da pandemia no transporte rodoviário, tanto no transporte de passageiros como de carga. Nesse ponto, se destaca que no comércio interno, as principais riquezas do país são movimentadas via esse modal devido aos baixos custos em relação a outros modais. Ao mesmo tempo, a crise revelou fatores devem ser ponderados e considerados no sentido de evoluir como país visando analisar alternativas no uso de transporte que tenda minimizar os custos de transporte. 
Research, Society and Development, v. 11, n. 1, e26111124732, 2022

(CC BY 4.0) | ISSN 2525-3409 | DOI: http://dx.doi.org/10.33448/rsd-v11i1.24732

Figura 5 - Mudança percentual nas exportações via modal rodoviário valor FOB US\$, estados de São Paulo, Rio de Janeiro e Minas Gerais. 2018 -2019, 2019-2020.
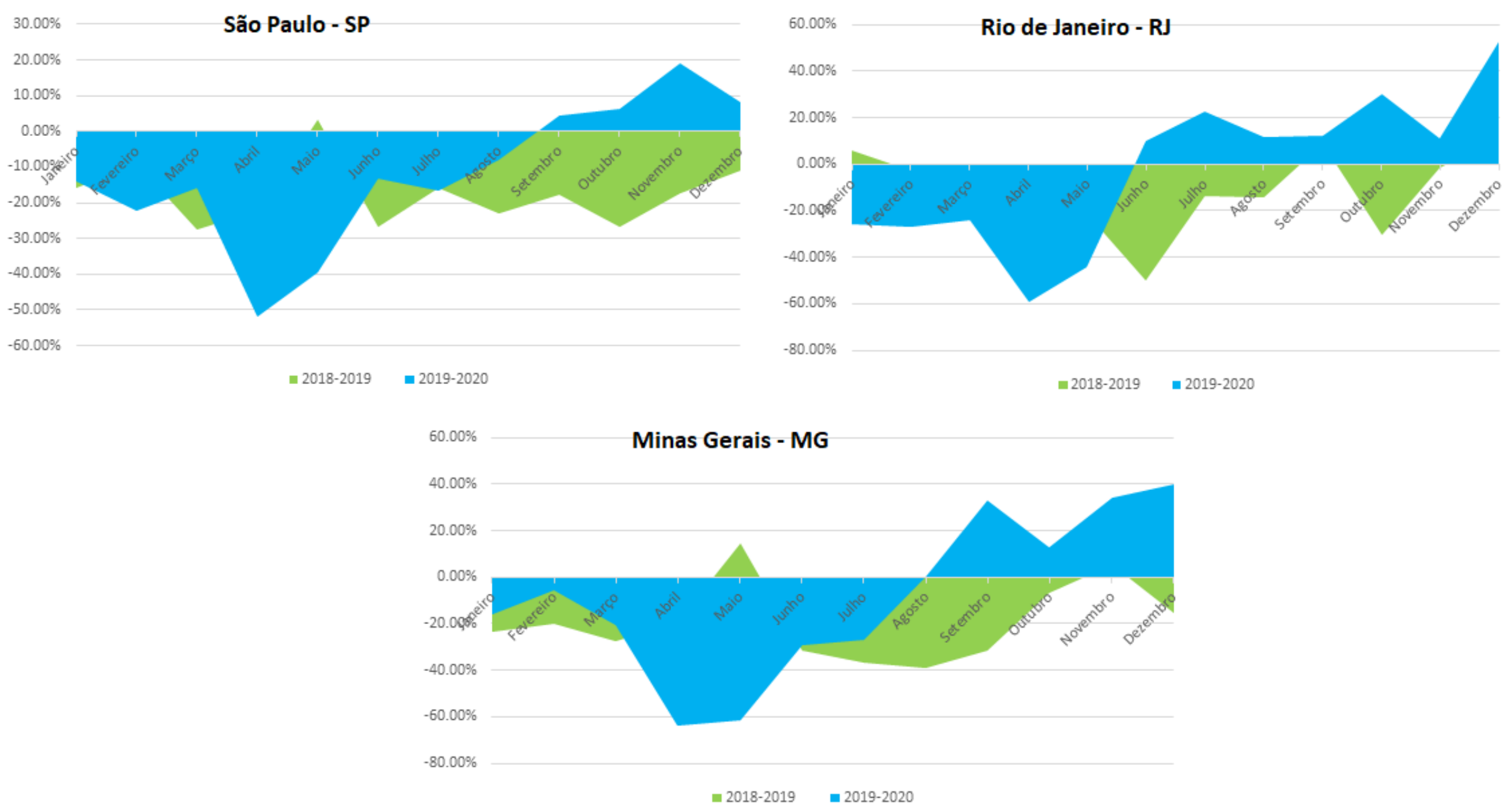

Fonte: Elaborado com dados do MDIC (2021). 


\subsection{Transporte aéreo. Estados de São Paulo, Rio de Janeiro e Minas Gerais.}

No caso do transporte aéreo, foi por sua vez o modal mais afetado. As medidas adotadas para a evitar a disseminação do vírus afetaram significantemente esse setor, resultado disso pode ser verificado na figura 6 . Em referida figura se verifica para os estados de São Paulo e Rio de Janeiro diminuição do uso desse modal em 2020 respeito a 2019. Nesse contexto, não somente o setor exportador sofreu os efeitos da pandemia, mas também, empresas vinculadas ao setor de turismo e lazer se vieram a afetadas, e ao mesmo tempo tendo observado uma grande diminuição das receitas nesse período.

Já de forma diferente, em 2019 respeito a 2018, se observa uma mudança positiva em determinados meses dos anos e, essa variação positiva decai posterior ao mês de agosto nos estados de São Paulo e Rio de Janeiro. No caso do estado de Minas Gerais se observa diversas variações ao longo dos meses, sendo que no geral, as mudanças são positivas, ou seja, existe um avanço no uso desse modal como meio de transporte para o comércio.

Aspecto importante a ser destacado, está relacionado aos tipos de produtos que são exportados via esse modal. De acordo com informações coletas na plataforma Comexstat do MDIC (20210), o modal é utilizado para transportar produtos de maior valor agregado, ante tal, as medidas adotadas para superar as barreiras ao comércio foram essenciais no sentido de não agravar dificuldades de embarques nas exportações. 
Research, Society and Development, v. 11, n. 1, e26111124732, 2022

(CC BY 4.0) | ISSN 2525-3409 | DOI: http://dx.doi.org/10.33448/rsd-v11i1.24732

Figura 6 - Mudança percentual nas exportações via modal aéreo valor FOB US\$, de São Paulo, Rio de Janeiro e Minas Gerais. 2018-2019, 2019 -2020.
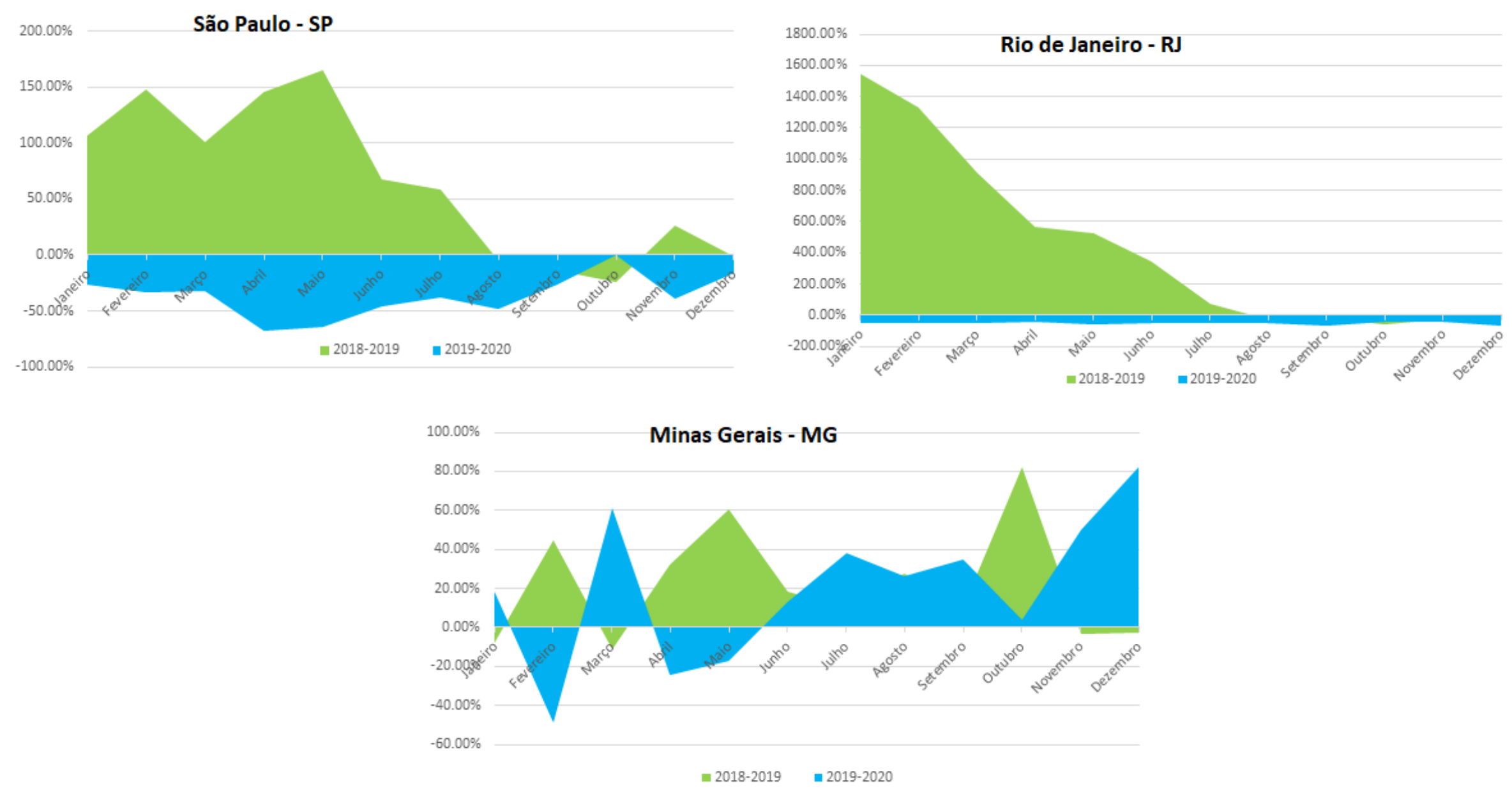

Fonte: Elaborado com dados do MDIC (2021). 


\section{Análise do market share da Exportação Segundo Modal de Transporte, Principais Estados. 2018-} 2020.

A metodologia usada para discutir as mudanças no padrão de exportação segundo tipo de modal foi o Market Share na forma simplificada. Ao falarmos do modelo em tela, ligamos o procedimento ao modelo Constant Market Share (CMS) sendo o pioneiro Tyszynski (1951) ao realizar um estudo voltado ao comércio internacional. Posteriormente, outros autores como Leamer e Stern (2008) desenvolveram versões a partir da ideia inicial, os quais são conhecidos como análise de segundo e de terceiro nível. No cenário Brasileiro, essa metodologia foi utilizada em estudos voltados a analisar o comércio exterior brasileiro, bem como, verificar mudanças no nível de competitividade por produtos (Arevalo et al., 2016; Chang, 2011)

No estudo em questão, foi utilizado o modelo em sua forma básica com a finalidade de atender a proposta do estudo. Para o estado de São Paulo (vide tabela 1) se verifica perda de market share via modal marítimo e rodoviária para o período 2019/2020 e ganho de participação via modal aéreo. No geral, se verifica também, perda de competividade ao comparar a queda das exportações do estado em comparação a média do Brasil, a exemplo tem-se -2,97\% para o Brasil via modal marítimo e -7,67\% para o estado de São Paulo.

Tabela 1 - Market share das exportações brasileiras segundo modal de transporte, comparativo com o estado de São Paulo.

\begin{tabular}{lccc}
\hline \multicolumn{1}{c}{ Dados do comércio } & Marítima & Rodoviária & Aérea \\
\cline { 2 - 4 } & 2018/2019 a 2019/2020 & $2018 / 2019$ a 2019/2020 & $2018 / 2019$ a 2019/2020 \\
\hline (A) Exportação & & & $-9,53 \%$ \\
Exportação brasileira (em \%) & $-2,97 \%$ & $-13,02 \%$ & -1.565 .840 .252 \\
Exportação brasileira (US\$ FOB) & -5.728 .584 .836 & -1.728 .494 .325 & $-5,74 \%$ \\
Exportação SP (em \%) & $-7,67 \%$ & $-15,70 \%$ & -448.898 .727 \\
Exportação SP (US\$ FOB) & -1.092 .460 .586 & -898.775 .136 & Aumentou de 47,62\% \\
& & & Para 49,61\% \\
(B) Market share - SP & Queda de 18,47\% & Queda de 43,11\% & para 41,78\% \\
\end{tabular}

Fonte: Elaborado com dados do MDIC (2021).

Para o estado do Rio de Janeiro (conforme a tabela 2) se verifica perda de market share via modal marítimo e aéreo para o período 2019/2020 e ganho de participação via modal rodoviário. No geral, se verifica também, perda de competividade ao comparar a queda das exportações do estado em comparação a média do Brasil, a exemplo tem-se $-2,97 \%$ para o Brasil via modal marítimo e $-8,41 \%$.

O valor do item B definido como market share, denota a participação de cada estado no total nacional. Assim, pode ser observar que somente no modal rodoviário teve mudança positiva. Entretanto, a participação do estado de RJ no total nacional é baixa quando comparamos com o grau de participação do estado de SP. 
Tabela 2 - Market share das exportações brasileiras segundo modal de transporte, comparativo com o estado do Rio de Janeiro.

\begin{tabular}{lccc}
\hline \multicolumn{1}{c}{ Dados do comércio } & Marítima & Rodoviária & Aérea \\
\cline { 2 - 4 } & $2018 / 2019$ a 2019/2020 & $2018 / 2019$ a 2019/2020 & $2018 / 2019$ a 2019/2020 \\
\hline (A) Exportação & $-2,97 \%$ & & $-9,53 \%$ \\
Exportação brasileira (em \%) & -5.728 .584 .836 & $-13,02 \%$ & -1.565 .840 .252 \\
Exportação brasileira (US\$ FOB) & $-8,41 \%$ & -1.728 .494 .325 & $-11,61 \%$ \\
Exportação RJ (em \%) & -830.542 .623 & $-8,74 \%$ & -272.360 .588 \\
Exportação RJ (US\$ FOB) & & -29.984 .658 & Queda de 14,28\% \\
(B) Market share - RJ & Queda de 12,80\% & Aumentou de 2,58\% & para 13,96\% \\
& para 12,08\% & para 2,71\% &
\end{tabular}

Fonte: Elaborado com dados do MDIC (2021).

Para o estado de Minas Gerais (vide Tabela 3) se verifica perda de market share via modal rodoviário para o período 2019/2020 e ganho de participação via modal aéreo e marítimo. No geral, se verifica também, ganho de competividade ao comparar a alta das exportações do estado em comparação a média nacional para os modais marítimo e aéreo, a exemplo, temse $-2,97 \%$ para o Brasil via modal marítimo e 3,79\% para o estado de Minas Gerais.

Ao igual que no estado de RJ, o estado de MG também tem baixa participação nas exportações via modal rodoviário, sendo destaque o estado de SP com um percentual médio de 42\%, aproximadamente. Dos três estados analisados, o estado de MG é o único que apresentam ganho de market share via modal marítimo, a saber, as exportações via esse com origem no estado de MG tiveram melhor desempenho que a média nacional.

Tabela 3 - Market share das exportações brasileiras segundo modal de transporte, comparativo com o estado de Minas Gerais.

\begin{tabular}{lccc}
\hline \multicolumn{1}{c}{ Dados do comércio } & Marítima & Rodoviária & Aérea \\
\cline { 2 - 4 } (A) Exportação & $2018 / 2019$ a 2019/2020 & $2018 / 2019$ a 2019/2020 & $2018 / 2019$ a 2019/2020 \\
Exportação brasileira (em \%) & & & $-9,53 \%$ \\
Exportação brasileira (US\$ FOB) & $-2,97 \%$ & $-13,02 \%$ & -1.565 .840 .252 \\
Exportação MG (em \%) & -5.728 .584 .836 & -1.728 .494 .325 & $17,40 \%$ \\
Exportação MG (US\$ FOB) & $3,79 \%$ & $-16,94 \%$ & 298.596 .651 \\
& 335.305 .252 & -124.090 .712 & Aumento de $10,45 \%$ \\
(B) Market share - MG & & & Para 13,56\% \\
& Aumento de 11,46\% & Queda de 5,52\% & Para 5,27\% \\
\hline
\end{tabular}

Fonte: Elaborado com dados do MDIC (2021).

\section{Considerações Finais}

O estudo teve por finalidade analisar mudanças no padrão de comércio no Brasil e principais estados que detém um maior percentual de participação na pauta exportadora. Prévio a definição dos estrados que são objeto de estudo, se realizou uma análise geral por estados com a finalidade de verificar os estados com maior participação no nível de exportação brasileiro e, ante o qual foi definido como objeto de estudo os estados de São Paulo, Rio de Janeiro e Minas Gerais.

Constatou-se, que o Brasil experimentou um recuo considerável no padrão de exportação via modal rodoviário em maior percentual ao comprar com o aéreo e marítimo. Para o intervalo de tempo analisado se verificou que a queda foi de $13,02 \%$ via modal rodoviário, sendo a crise sanitária e as medidas restritivas para conter o avanço da pandemia o principal 
fator que explique esse despenho. A saber, o fechamento das fronteiras e cidades, afetaram toda a cadeia produtiva da economia e sendo o modal de transporte rodoviário quem mais sofreu nesse período.

O resultado do Market Share por estados evidenciou a grande participação na pauta de exportação do estado de São Paulo. Além disso, a relevância dos modal marítimo, já que mediante esse modal se destina a maior parte das exportações. No geral, e de forma complementar, o efeito China influenciou na quantidade exportada, fato resultante foi um choque de oferta experimentado pelo setor minério e também no agronegócio.

Finalmente, cabe ressaltar algumas limitações da metodologia utilizada, das quais menciona-se ao market share como uma proxy da competitividade e, em muitos casos pode levar a diferentes conclusões. Outro fator a observar é o período estipulado em análise, a qual pode varias a interesse do pesquisador, consequentemente, os resultados serão diferentes. Dado a matriz de competitividade brasileira, existe a possibilidade de dar continuidade a esse estudo analisando produtos por estados em função da desagregação do sistema harmonizado de comércio, o qual ajudaria a revelar o nível especifico de competitividade.

\section{Referências}

Arevalo, J. L. S., Arruda, D. de O., \& de Carvalho, J. P. (2016). Competitividade no comércio internacional do café: um estudo comparativo entre Brasil, Colômbia e Peru. Organizações Rurais \& Agroindustriais, 18(1).

Ashwani, P. S. (2020). COVID-19 and Indian Economy: Impact on Growth, Manufacturing, Trade and MSME Sector. Global Business Review, 21(5) 11591183 p.

Bresser-Pereira, L. C. (2020). Financing COVID-19, inflation and fiscal constraint. Brazilian Journal of Political Economy, 40(4), 604-621.

Borca, B., Putz, L.-M., Hofbauer, F. (2021). Crises and Their Effects on Freight Transport Modes: A Literature Review and Research Framework. Sustainability, vol., 13, 5740p.

Brasil. (2021). Associação brasileira de transportes internacionais - ABTI. Cenário do transporte, edição 2 do trimestre 2020. http://www.abti.com.br/images/cenario-do-transporte/pdfs/56.pdf.

Brasil. (2021). Agência Nacional de Transportes Aquaviários - ANTAQ. Movimentação portuária.: https://www.gov.br/antaq/ptbr/noticias/2021/movimentacao-portuaria-cresceu-10-5-no-1o-trimestre-diz-antaq.

Brasil. (2021). Câmara de comércio e indústria, Brasil - Portugal (CBPCE). Informações de comércio exterior. https://cbpce.org.br/tag/cabotagem/.

Brasil. (2021). Confederação Nacional da Indústria - CNI. Publicações. https://www.portaldaindustria.com.br/publicacoes/.

Brasil. (2021). Confederação Nacional de Transporte. CNT lança painel com dados do transporte rodoviário no Brasil. https://cnt.org.br/agencia-cnt/cnt-lancapainel-com-dados-do-transporte-rodoviario-no-brasil.

Brasil. (2021). Ministério da Agricultura, Pecuária e Abastecimento - MAPA. Plataforma Agrostat. Estatísticas de comércio exterior do agronegócio brasileiro. https://sistemasweb.agricultura.gov.br/pages/AGROSTAT.html.

Brasil. (2021). Ministério da Indústria, Comércio Exterior e Serviços - MDIC. Plataforma Comexstat. Estatísticas do Comércio Exterior Brasileiro. http://comexstat.mdic.gov.br/pt/home.

Brasil. (2021). Ministério da Infraestrutura. Anuário Estatístico de Transportes - MINFRA.: https://www.gov.br/infraestrutura/pt-br/assuntos/dados-detransportes/anuario-estatistico-2.

Chang, Mateus Silva. (2011). Exportações brasileiras para a China e o Japão: padrões de especialização e competividade. Dissertação (Mestrado em Economia Aplicada) - Escola Superior de Agricultura Luiz de Queiroz, Universidade de São Paulo, Piracicaba, Brasil.

Leamer, E. E., Stern, R. M. (2008). Quantitative international economics. (2a ed.), Transaction Publisher.

Loaiza, J. R., Rao, K., Eskildsen, G. A., Ortega-Barria, E., Miller, M. J., \& Gittens, R. A. (2020). COVID-19 pandemic in Panama: lessons of the unique risks and research opportunities for Latin America. Revista Panamericana De Salud Publica-Pan American Journal of Public Health, $44,1$.

Nimorakiotaki, D., \& Sambracos, E. (2020). Demand on Public Transportation during the Economic Crisis: The Greek Case. European Research Studies Journal, Volume XXIII, Special Issue 2.

Notteboom, T., Pallis, T., \& Rodrigue, J. P. (2021). Disruptions and resilience in global container shipping and ports: the COVID-19 pandemic versus the 2008-2009 financial crisis. Maritime Economics \& Logistics, volume 23, pages179-210.

ONU. Organização das Nações Unidas. Transporte marítimo perfaz mais de 80\% do comércio global. https://news.un.org/pt/story/2020/09/1727312. 
Research, Society and Development, v. 11, n. 1, e26111124732, 2022

(CC BY 4.0) | ISSN 2525-3409 | DOI: http://dx.doi.org/10.33448/rsd-v11i1.24732

Pereira, R. H. M., Warmar, L., Parga, J., Bazzo, J., Braga, C. K., Herszenhut, D., Saraiva, M. (2021). Tendências e desigualdades da mobilidade urbana no Brasil I: o uso do transporte coletivo e individual. Texto para discussão / Instituto de Pesquisa Econômica Aplicada-Brasília: Ipea.

Rodrigues Pinto, Alexandre, Alves dos Santos, Tainá, \& Dai Prá Martens, Cristina. (2021). Impactos da pandemia de COVID-19 sobre o empreendedorismo digital nas instituições bancárias brasileiras: uma análise à luz das forças isomórficas. Estudios Gerenciales, 37(158), 113-125.

Tyszynski, H. (1951). World Trade in Manufactured Commodities, 1899-1950. The Manchester School of Economic and Social Studies, 19, 222-304p. 